\title{
miR-320b suppresses cell proliferation by targeting c-Myc in human colorectal cancer cells
}

\author{
Hantao Wang $^{1 \dagger}$, Fuao $\mathrm{CaO}^{1 \dagger}, \mathrm{Xu} \mathrm{Li}^{1 \dagger}$, Hua Miao ${ }^{2}$, Jifu $\mathrm{E}^{1}$, Junjie Xing ${ }^{1}$ and Chuan-gang $\mathrm{Fu}^{1 *}$
}

\begin{abstract}
Background: MicroRNAs (miRNAs) are small noncoding RNAs that potentially play a critical role in tumorigenesis. Mounting evidence indicates that one specific miRNA: miR-320b is down regulated in numerous human cancers, including colorectal cancer (CRC); making the hypothesis that miR-320b may play a key role in tumorigenesis plausible. However, its role in carcinogenesis remains poorly defined. The goal of this study is to better clarify the role of miR-320b in tumor growth of CRC.

Methods: Quantitative reverse-transcription polymerase chain reaction (qRT-PCR) was conducted to detect the expression of miR-320b in CRC tissues and 5 CRC cell lines. The effect of miR-320b on cell proliferation was analyzed in vitro and in vivo. Furthermore, a luciferase reporter assay was performed to measure the target effects of miR-320b. Lastly, the messenger RNA (mRNA) and protein levels of the gene c-MYC were measured in CRC cell lines and tissues by qRT-PCR, and confirmed via Western blot and Immunohistochemical (IHC) staining.
\end{abstract}

Results: The results presented here showed that miR-320b expression was down regulated in both CRC tissues and cells. Overexpression of miR-320b in CRC cells was statistically correlated with a decrease of cell growth in vitro and in vivo, while c-MYC was identified as a target gene of miR-320b in CRC. Furthermore, it was found that up-regulation of c-Myc can attenuate the effects induced by miR-320b.

Conclusions: Our identification of c-MYC as a target gene of miR-320b provides new insights into the pathophysiology of CRC proliferation, and identifies miR-320b as a novel therapeutic target for the treatment of CRC.

Keywords: Colorectal cancer (CRC), miR-320b, c-Myc, Cyclin D1

\section{Background}

Colorectal cancer (CRC) is one of the most common cancers, and accounts for approximately $9.4 \%$ of all cancer cases worldwide. According to the International Agency for Research on Cancer (IARC), approximately 1 million new cases are detected each year $[1,2]$. There has been considerable effort devoted to investigating the biological mechanisms responsible for promotion of CRC; however, the detailed mechanisms underlying CRC pathogenesis remain elusive.

MicroRNAs (miRNAs) are a class of small RNAs ( 22 nucleotides) down regulates the expression of their target genes through mRNA degradation or translational inhibition [3, 4]. The target site of miRNA has been

\footnotetext{
*Correspondence: fugang416@126.com

'Equal contributors

'Department of Colorectal Surgery, Changhai Hospital, Shanghai 200433, China

Full list of author information is available at the end of the article
}

considered to be the $3^{\prime}$ un-translated region (3' UTR) of mRNA. However, increasing evidence shows that miRNAs may also bind the coding regions or the $5^{\prime}$ un-translated region (5' UTRs) $[5,6]$. Mounting evidence indicates that post-translational regulation of gene expression mediated by miRNAs acts as either a tumor suppressor or an oncogene in CRC [7-11]. Several miRNAs found in CRC such as miR-451, miR-34, miR-135, miR-122, let-7a, miR-143, miR-17-92, miR-101, miR-126, miR-200, miR-203, miR183 and miR-21 have been shown to have an effect on cell growth and apoptosis; as well as invasion and migration [11]. Previous studies have shown that miR-320b is significantly down regulated in several cancers including CRC [12], glioblastoma [13], gastric cancer [14] and bladder cancer [15]. Given that down regulation of miR-320b is common in a number of cancers, it has been hypothesized that miR-320b may play an important role in tumor development and tumorigenesis.

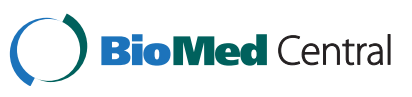

(c) 2015 Wang et al. Open Access This article is distributed under the terms of the Creative Commons Attribution 4.0 International License (http://creativecommons.org/licenses/by/4.0/), which permits unrestricted use, distribution, and reproduction in any medium, provided you give appropriate credit to the original author(s) and the source, provide a link to the Creative Commons license, and indicate if changes were made. The Creative Commons Public Domain Dedication waiver (http://creativecommons.org/publicdomain/zero/1.0/) applies to the data made available in this article, unless otherwise stated. 
In this study, we evaluated the miR-320b expression levels in tumor tissues from 48 CRC patients and found that miR-320b was significantly down regulated in these tissues. Additionally, it was found that the overexpression of miR-320b in CRC cells was correlated with observed decreases in cell growth both in vitro and in vivo. This study also demonstrated that $c-M Y C$ was directly targeted by miR-320b, and that overexpression of miR$320 \mathrm{~b}$ in CRC cells decreased both mRNA production, and protein expression of $c-M Y C$. These findings strongly suggested that miR-320b inhibited proliferation of CRC cells through an inhibition of $c-M Y C$ gene function, and that increasing miR-320b expression levels may provide a novel approach for CRC treatments.

\section{Methods}

\section{Tissue samples and cell lines}

A total of 48 CRC tissue samples and their adjacent non-tumor tissues were obtained from Department of Colorectal Surgery, Changhai Hospital (Shanghai, China) for qRT-PCR analysis. All tissue samples were obtained surgically and immediately snap frozen and stored in liquid nitrogen until use. The study protocol was approved by Shanghai Changhai Hospital Ethical Committee, and written informed consent was obtained from all subjects before the study was conducted. Additionally, five normal colorectal tissues were obtained from non-cancer patients by colonoscopy. For the in vitro experiments, cell lines including HCT-116, SW-480, SW-620, LoVo and HEK293 were used and were purchased from American Type Culture Collection (ATCC). SW-480 and SW-620 were cultured in Leibovitz's L-15 medium containing $10 \%$ FBS. HCT-116 and LoVo cells were cultured in Ham's F12K medium containing $10 \%$ FBS, and HEK293 cells were cultured in DMEM medium containing 10 \% FBS. All cells were maintained at $37^{\circ} \mathrm{C}$ in a humidified atmosphere with $5 \% \mathrm{CO}_{2}$.

\section{RNA quantification}

Total RNA was isolated using a Trizol extraction kit (Life Technologies, USA) according to the manufacturer's instructions. Purified mRNA and miRNAs were detected by qRT-PCR assay using All-in-One miRNA qRT-PCR Detection Kit (GeneCopoeia, USA). U6 small RNA was used as an internal control for normalization and quantification of miR-320b expression. As an internal control $\beta$-actin was measured for normalization and quantification of c-Myc expression.

\section{Luciferase reporter assay}

The luciferase reporter was constructed by cloning human $c-M Y C$ cDNA sequence into pMIR-Report (Ambion, Austin, USA). Wild type or mutant $c-M Y C$ mRNA fragments were amplified and cloned into the luciferase reporter via Spe $I$ and Hind III sites. Luciferase reporter assays were performed as following, HEK293 and SW-480 cells were plated in a 96-well plate and co-transfected with $50 \mathrm{nM}$ single-stranded miRNA mimics, or negative control oligonucleotides, with $10 \mathrm{ng}$ of firefly luciferase reporter and 3 ng of pRL-TK (Promega, USA) using the JetPRIME reagent (Polyplus-transfection). Cells were harvested $48 \mathrm{~h}$ after the transfection and analyzed using Dual-Luciferase Reporter Assay System (Promega, Japan).

\section{Oligonucleotide and plasmid transfection}

RNA oligos were chemically synthesized and purified by (Genepharma, China). Sense sequence of human miR320b mimics was 5' - AAA GCU GGG UUG AGA GGG CAA - 3 ' and antisense sequence was 5'- UUG CCC UCU CAA CCC AGC UUU U-3'. Negative control oligonucleotides were 5'-AAU UCU CCG AAC GUG UCA CTT-3' and 5'-GUG ACA CGU UCG GAG AAU UTT3'. The transfections were performed with INTERFERin reagent (Polyplus-transfection). The final concentration of miRNA was found to be $50 \mathrm{nM}$.

To generate pGL3-c-MYC constructs, the coding DNA sequence fragment of $c-M Y C$ was amplified and inserted into the KpnI and XhoI sites of the pGL3 construct. All constructs were verified by direct sequencing. Finally, the transfections were conducted using INTERFERin reagent (Polyplus-transfection, France). The final concentration of plasmids was diluted to $100 \mathrm{ng}$.

\section{MTT assay}

To measure in vitro growth of CRC cells, the MTT assay was used. A total of $5 \times 10^{3}$ cells were seeded into each well of 96-well plates and transfected with miR-320b mimics or negative control oligonucleotides at a final concentration of $50 \mathrm{nM}$ respectively. On the day of measurement, $100 \mu \mathrm{l}$ of spent medium was replaced with an equal volume of fresh medium containing $0.5 \mathrm{mg} / \mathrm{ml} \mathrm{MTT}$. Plates were incubated at $37^{\circ} \mathrm{C}$ for $4 \mathrm{~h}$, then the medium was replaced with $100 \mu \mathrm{l}$ of DMSO (Sigma, USA), and were then shaken at room temperature for $10 \mathrm{~min}$. Absorbance was then measured at a wavelength of $570 \mathrm{~nm}$.

\section{Tumorigenicity assay in Non Obese Diabetic (NOD) mice}

All mice were cared and maintained according to the National Institute of Health Guide for the Care and Use of Laboratory Animals, with the approval of the Scientific Investigation Board of Second Military Medical University, Shanghai. Cholesterol-conjugated miR-320b mimics and negative control oligonucleotides transfected SW-480 cells $\left(1 \times 10^{6}\right)$ were suspended in $150 \mu \mathrm{l}$ PBS and then injected subcutaneously into either side of the posterior flank of the same Non obese diabetic (NOD) 6 week old mice. Mice were examined every three days over a course of 4 weeks. Tumor volume (V) was monitored by measuring 
Table 1 Patients' characteristics of clinical-pathologic features

\begin{tabular}{llc}
\hline Characteristics & No. of patients $(n=48)$ & Percent (\%) \\
\hline Age at diagnosis (year) & & \\
$\quad \leq 60$ & 21 & 43.8 \\
$>60$ & 27 & 56.2 \\
Sex & & \\
$\quad$ Male & 25 & 52.1 \\
$\quad$ Female & 23 & 47.9 \\
Tumor Size(cm) & & \\
$\geq 3 \leq 3$ & 6 & 12.5 \\
$>3$ and $\leq 5$ & 28 & 58.3 \\
$>5$ & 14 & 29.2 \\
\hline
\end{tabular}

the length (L) and width (W) of the tumor with calipers and was calculated with the formula $V=(L \times W 2) \times 0.5$.

\section{Western blot}

Protein from tissue and cells was separated in a $12 \%$ SDSPAGE gel and transferred onto a nitrocellulose membrane (Bio-Rad, Hercules, USA). The membrane was blocked with $5 \%$ non-fat milk and incubated with anti-c-Myc antibody, anti-Cyclin D1 (Santa Cruz, CA) or anti- $\beta$-actin antibody (Sigma, CA, USA). After being washed extensively, a goat anti-mouse secondary antibody (Pierce, IL, USA) was added to the system. The proteins were detected using ECL reagents (Pierce).

\section{Immunohistochemical (IHC) staining}

Paraffin-embedded tissue sections were deparaffinized in xylene and rehydrated in graded series of ethanol followed by heat induced epitope retrieval in citrate buffer (PH 6.0). Sections were incubated at $4{ }^{\circ} \mathrm{C}$ overnight with monoclonal antibodies against c-Myc (Santa Cruz, CA) and Ki-67 (Cell Signaling Technology, Danvers, MA).
Immunostaining was performed using ChemMate DAKO EnVision Detection Kit, Peroxidase/DAB, Rabbit/Mouse (code K 5007, DakoCytomation, Glostrup, Denmark) according to the manufacturer's instructions. Subsequently, sections were counterstained with hematoxylin (Dako) and mounted in dimethyl benzene.

\section{Statistical analysis}

All statistical analyses were carried out using the SPSS 16.0 statistical software package. Continuous variables were expressed as mean \pm SEM. Differences between groups were calculated with Student's $t$ test. A two-tailed $P$ value test was used with a $P$ value of $<0.05$ considered statistically significant.

\section{Results}

The expression of miR-320b is down regulated in CRC In order to identify the role of miR-320b in CRC carcinogenesis, the expression of miR-320b in CRC samples (patient details have been listed in Table 1) and cell lines was analyzed. As shown in Fig. 1a, miR-320b was significantly decreased in CRC tissues versus adjacent nontumor tissues. It was also shown that miR-320b was down-regulated in 4 CRC cell lines, when compared with 5 normal colorectal tissues (Fig. 1b). These observations suggest that miR-320b may be an oncosuppressor in CRC.

\section{miR-320b inhibits CRC growth in vitro and in vivo}

To investigate the effect of miR-320b on CRC proliferation, miR-320b mimics or negative control oligonucleotides were transiently transfected into two human CRC cell lines, HCT-116 and SW-480. Measurements of RNA expression levels using qRT-PCR (primer sequences have been listed in Table 2) showedd that transfection of miR-320b mimics significantly increased its expression in HCT-116 and SW-480 cells (Fig. 2a). In the cell
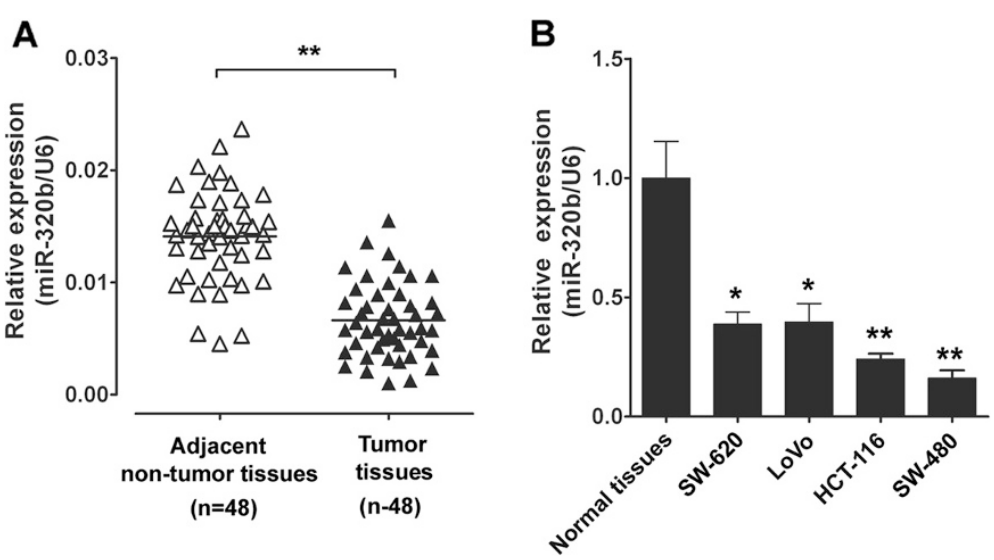

Fig. 1 miR-320b is down-regulated in CRC samples and cell lines. a Expression of miR-320b was measured in 48 CRC and adjacent non-tumor tissues by qRT-PCR. $\mathbf{b}$ The expression levels of miR-320b were further measured in 5 normal tissues and 4 CRC cell lines by qRT-PCR. Data analyzed using Student's $t$-test. ${ }^{*} p<0.05,{ }^{* *} p<0.01$ 
Table 2 All primers used in this study

\begin{tabular}{ll}
\hline Name & Primer sequence \\
\hline U6 F & 5'- GTGCTCGCTTCGGCAGCACATATAC -3' \\
U6 R & 5'-AAAAATATGGAACGCTTCACGAATTT -3' \\
$\beta$-actin F & 5'-AGAGCTACGAGCTGCCTGAC-3' \\
B-actin R & 5'-AGCACTGTGTTGGCGTACAG-3' \\
c-Myc (WT) F & 5'-GGCTAGTGATGCCCCTCAACGTTAGCTT-3' \\
c-Myc (WT) R & 5'-AAAAGCTT GTAGTCGAGGTCATAGTTCC-3' \\
c-Myc (MUT) F & 5'-GGCTAGTGATCGGGGAGTTGGTTCGATCACC-3' \\
c-Myc (MUT) R & 5'-AAAAGCTT GTAGTCGAGGTCATAGTTCC-3' \\
c-Myc (pGL3) F & 5'-AAGGTACC ATGCCCCTCAACGTTAGCTTCACC-3' \\
c-Myc (pGL3) R & 5'-AACTCGAGTTACGCACAAGAGTTCCGTAGC-3' \\
miR-320b F & 5'-AAAAGCTGGGTTGAGAGGGCAA-3' \\
\hline
\end{tabular}

Abbreviations: $F$ forward primer, $R$ reverse primer, $W T$ wild type, MUT mutant proliferation assay, restoration of miR-320b in HCT-116 and SW-480 cells resulted in a significant suppression of cell proliferation. The proliferation rate was suppressed in HCT-116 and SW-480 cells after transfection with miR$320 \mathrm{~b}$, and the inhibitory efficiencies were $50.0(P<0.01)$ and $37.5 \%(P<0.01)$, respectively (Fig. $2 b)$.

Inhibition of cell growth in cancer cells is usually associated with concomitant cell cycle arrest. Cell cycle analysis was performed to determine whether the effect of miR-320b on cell proliferation was due to cell cycle arrest. Indeed, the result showed a G1 arrest, with $61.46 \%$ $\pm 7.66 \%$ of miR-320b-transfected cells in G0/G1 versus $43.51 \% \pm 5.59 \%$ of control HCT-116 cells. Similar effects of miR-320b were found in SW-480 cells, with $61.5 \% \pm$ $7.34 \%$ of miR-320b-transfected cells in G0/G1 versus $41.41 \% \pm 5.35 \%$ of control cells (Fig. 2c). These results
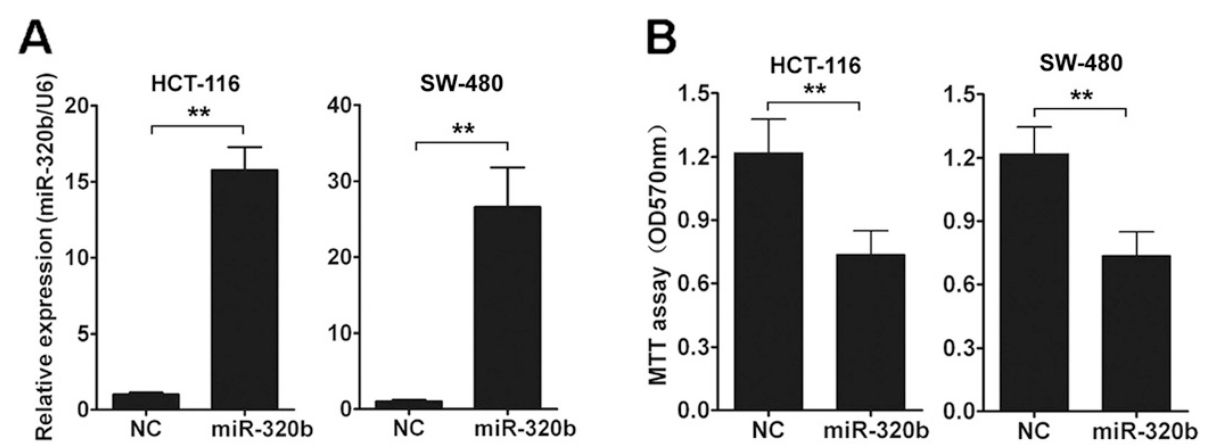

\section{HCT-116}
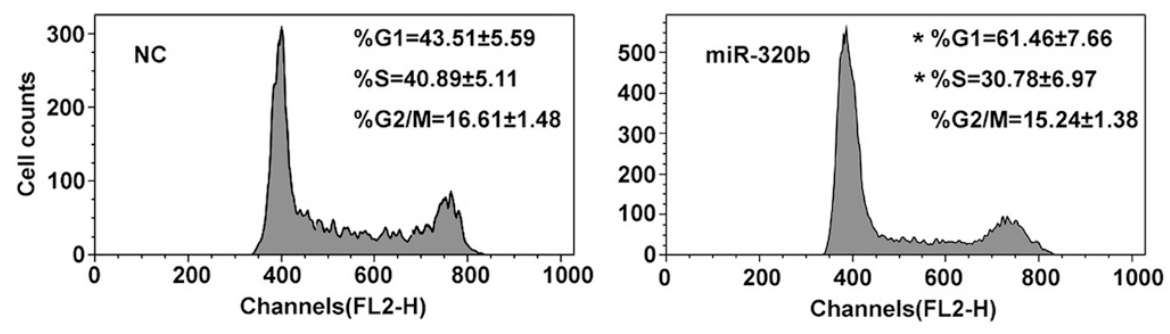

SW-480
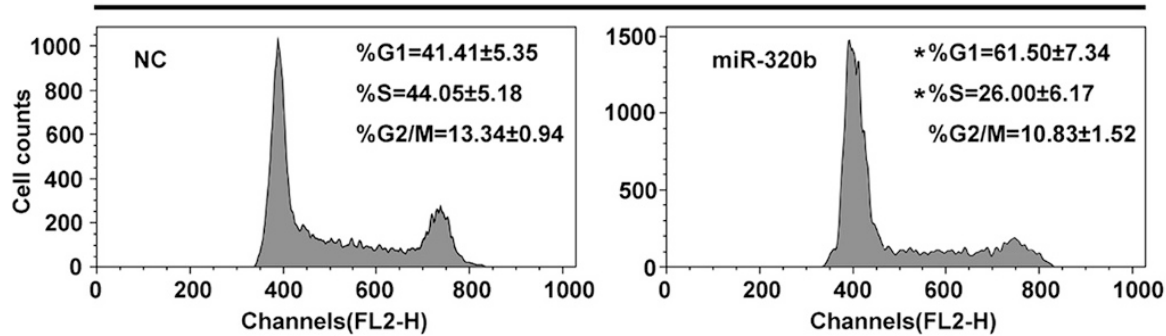

Fig. 2 miR-320b overexpression inhibits CRC cells growth in vitro. a miR-320b expression was quantified by qRT-PCR analysis 48 h. after transfection of miR-320b mimics (miR-320b) and negative control oligonucleotides (NC) in HCT-116 and SW-480 cells. b HCT-116 or SW-480 cells were transfected with miR-320b or NC. Cell proliferation was measured using the MTT assay after culturing for $72 \mathrm{~h}$. c Cell-cycle distribution was analyzed by FACS analysis. HCT-116 and SW-480 cells were transfected with miR-320b or NC. Nocodazole $(25 \mathrm{ng} / \mathrm{ml})$ was added $24 \mathrm{~h}$ after transfection for another $16 \mathrm{~h}$, then the supernatant was replaced by fresh medium for $6 \mathrm{~h}$. Data analyzed using Student's $t$-test.. $p<0.05,{ }^{* *} p<0.01$ 
demonstrated that the overexpression of miR-320b inhibits the growth of CRC cells.

To better understand the modulation of miR-320b in tumorigenisis, we used an in vivo model to evaluate the effect of tumorigenicity after overexpression of miR-320b. Cholesterol-conjugated miR-320b mimics and negative control oligonucleotides transfected SW-480 cells were injected subcutaneously into either side of the posterior flank of the same NOD mice. In this tumorigenicity assay $(n=3)$, when compared with negative control oligonucleotides $(n=3)$ transfectants, miR-320b transfected cells revealed a significant reduction in the tumor size (Fig. 3a, b) and cell proliferation (Fig. 3c), suggesting a potential tumor suppressive effect of miR-320b expression.

\section{Identification of c-Myc as miR-320b direct target in CRC}

To confirm miR-320b regulation of the expression of $c-M Y C$ gene, we first performed luciferase reporter assays in HEK293 and SW-480 cells. As shown in Fig. 4a and $b$, transfection of miR-320b caused a significant decrease in luciferase activity in cells transfected with the reporter plasmid with wild type targeting sequence of $c-M Y C$ mRNA but not reporter plasmid with mutant sequence of $c-M Y C$.
HCT-116 and SW-480 cells which demonstrated a lower expression of miR-320b (Fig. 1b) were transfected with miR-320b mimics or negative control oligonucleotides, and $c-M Y C$ mRNA as well as protein levels were examined by qRT-PCR and confirmed via western blotting. The levels of $c-M Y C$ mRNA and protein were consistently and substantially down regulated by miR-320b (Fig. 4c, d). Moreover, $c-M Y C$ mRNA levels were significantly increased in CRC tissues versus adjacent normal tissues which agreed with previous report [16]. Consistent with this finding, Fig. 4f showed a reversed correlation between miR-320b expression levels and $c-M Y C$ mRNA levels in CRC tissues $(r=-0.545, P<0.001)$. CRC tissues with low miR-320b consistently showed much higher $c-M Y C$ expression compared to normal tissues with high levels of miR-320b, but lower $c-M Y C$ expression (Fig. 4g). Taken together, our results demonstrated that c-Myc was a direct target of miR-320b in CRC cells.

\section{Restoration of miR-320b suppresses c-Myc-induced CRC proliferation}

This study has shown that overexpression of miR-320b suppressed the proliferation of CRC cells, and c-Myc was a direct target of miR-320b. We next explored the

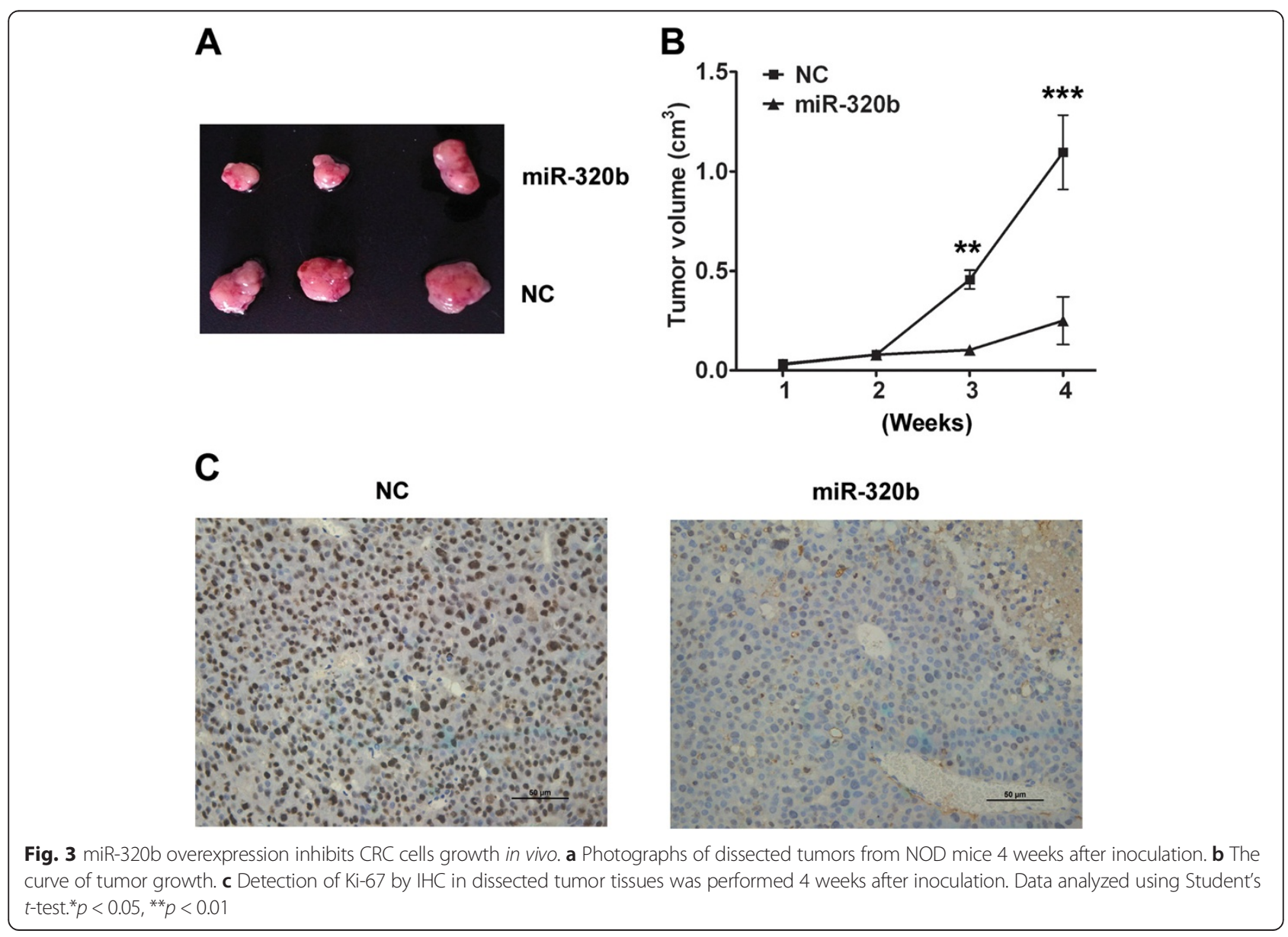


A

556-603 c-Myc mRNA(WT): 5'-ATGCCC---CTCAACGTTAGCTTCACCAACAGGAACTATGACCTCGACTAC-3'

IIII। IIII। IIII

miR-320b: 3'-AACGGGAGAGUUGGGUCGAAAA-5'

I

I

556-603 c-Myc mRNA(MUT): 5'-ATCGGG---GAGTTGGTTTCGATCACCAACAGGAACTATGACCTCGACTAC-3'

B

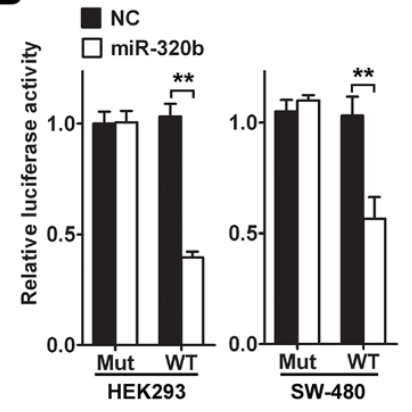

E

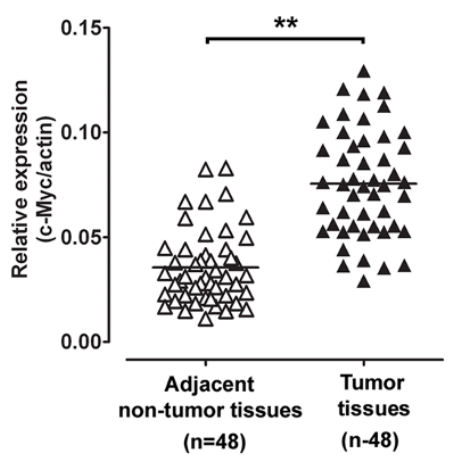

C $\rightarrow \mathrm{NC}$

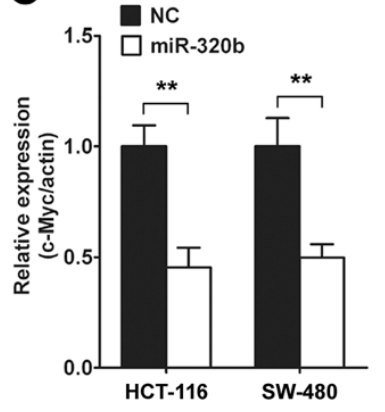

$\mathbf{F}$

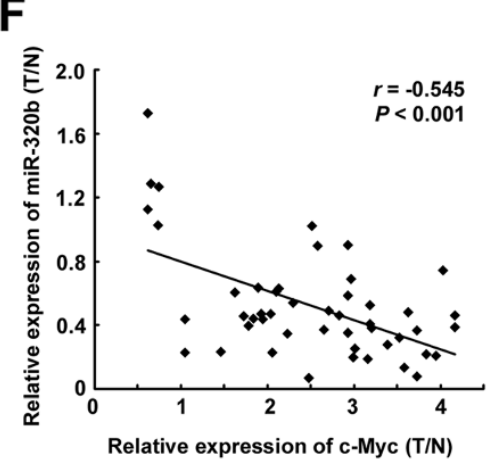

G

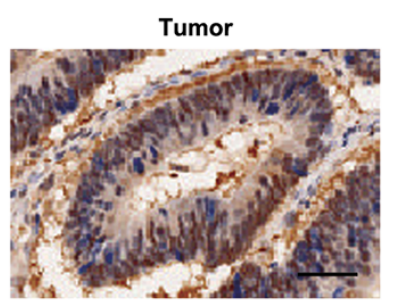

Adjacent non-tumor

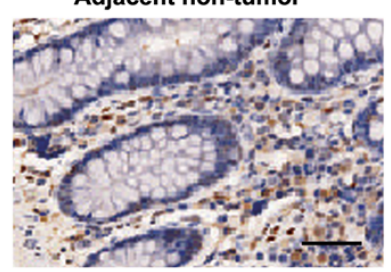

D

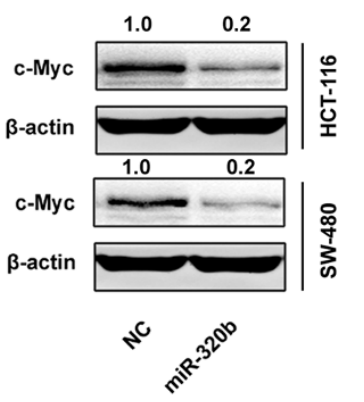

Fig. 4 miR-320b down-regulates c-Myc expression in CRC cells. a Wild-type (WT) and mutant (Mut) of putative miR-320b targeting sequences in c-Myc mRNA. Mutant sequences were shown in bold type. b Analysis of luciferase activity. HEK293 and SW-480 cells were co-transfected with miR-320b mimics (miR-320b) or negative control oligonucleotides (NC), pRL-TK and firefly luciferase reporter plasmid containing putative miR-320b targeting sequences of c-Myc. c, $\mathbf{d}$ The endogenous c-Myc mRNA (c) and protein (d) levels were quantified $48 \mathrm{~h}$. after transfection of (miR-320b) and (NC) in HCT-116 and SW-480 cells. e Expression of c-Myc was measured in 48 CRC and adjacent non-tumor tissues by qRT-PCR. f A negative Spearman correlation between miR-320b and c-Myc mRNA levels was found in CRC samples. $\mathbf{g}$ Analysis of c-Myc and miR-320b expression in the same CRC and adjacent non-tumor tissue by IHC and qRT-PCR. Brown signal in IHC was considered as positive staining for c-Myc. Scale bar $=50 \mu \mathrm{m}$. Data analyzed using Student's $t$-test. ${ }^{*} p<0.05,{ }^{* *} p<0.01$

inhibitory effect of miR-320b on CRC cells' viability. It was found that c-Myc protein levels in HCT-116 and SW-480 cells significantly increased as well as its targeting genes such as Cyclin D1(key factor in cell growth regulation $[17,18])$. At the mean time, restoration of the miR-320b expression levels in HCT-116 and SW-480 cells showed a markedly inhibited expression of c-Myc and Cyclin D1 (Fig. 5a). In line with these findings, miR320b significantly suppressed c-Myc-induced cell proliferation in HCT-116 and SW-480 cells (Fig. 5b). Together, these results demonstrated that miR-320b could regulate $\mathrm{CRC}$ cells growth through targeting c-Myc. 


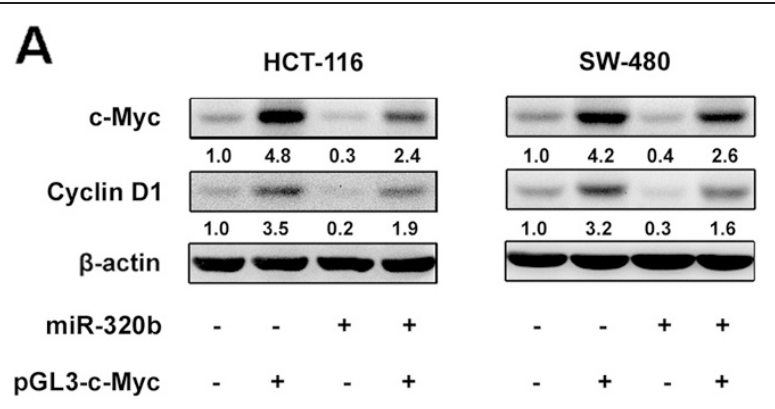

B

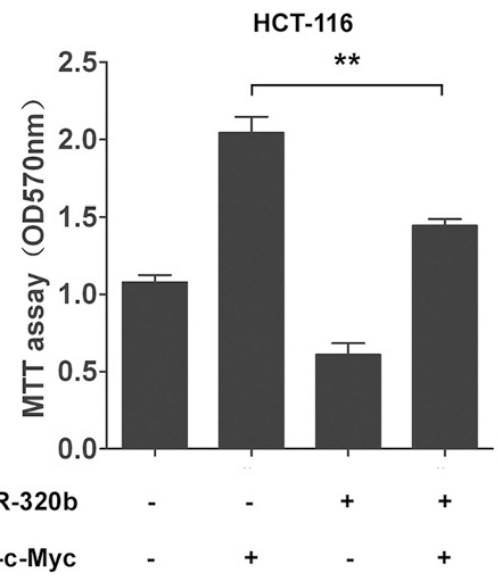

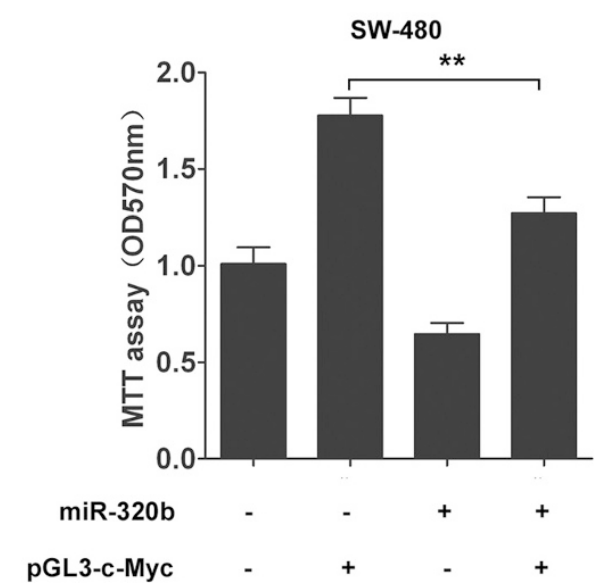

Fig. 5 miR-320b inhibits the proliferation of CRC cells by targeting c-Myc. a HCT-116 and SW-480 cells were transfected with miR-320b and/or PGL3-c-Myc, 48 h. later the expressions of c-Myc and Cyclin D1 were analyzed via western blotting. b HCT-116 andSW-480 cells were transfected with miR-320b and/or pGL3-c-Myc, and cell proliferation was measured by by MTT assay at $72 \mathrm{~h}$. after transfection. Data analyzed using Student's t-test. ${ }^{*} p<0.05,{ }^{* *} p<0.01$

\section{Discussion}

In this study, we examined the expression profile of miR-320b in CRC. Our results showed that miR-320b was down-regulated in CRC tissues as well as in 2 human CRC cell lines, which was similar with previous reports [12]. In addition, we identified c-Myc as a direct and functional target of miR-320b in CRC cells. Overexpression of miR-320b in CRC cells significantly inhibited the cell proliferation by down-regulating c-Myc.

The interest in understanding the role of miRNA in cancer cells and carcinogenesis has grown rapidly, so has the amount of studies in this field $[9,10]$. There has been reports showing that miR-320 is down regulated in several tumor types [12-15], and one of miR-320 's downstream effects was inhibiting cell proliferation by targeting transferrin receptor 1 (CD71) in human leukemia cell line HL-60 [19]. Additionally, it is known that miR-320 suppresses the stem cell like characteristics of prostate cancer cells by down regulating the Wnt/beta-catenin signaling pathway [20].

Deregulation of miRNAs has been indicated to be heavily involved in tumorigenesis and tumor development $[10,21,22]$. Our results showed that miR-320b was down- regulated in CRC, which prompted us to further investigate the role of miR-320b in CRC cells. In order to explore the underlying mechanisms of the silenced miR-320b in CRC, the CRC pathogenesis-related target genes were further analyzed. In a recent study, 18,000 high-confidence miRNAmRNA interactions in HEK 293 cells by CLASH were reported [23]. However, it remains unclear whether these miRNA pairings also exist in CRC cells. The CLASH data showed that 72 genes were targeted by miR-320b. Among these genes, we focused on $c-M Y C$, a central component of the MAPK/ERK pathway, which is involved in many cellular processes including cell growth, cell differentiation, apoptosis and other cellular functions [17]. From the CLASH data in HEK293 cells, the potential targeting sequence for miR-320b with a calculated energy of $-23.1 \mathrm{kcal} / \mathrm{mol}$ is within the protein coding region of cMyc mRNA from 556 to 603 [23]. This targeting mode is similar to miR-185-3p (a potential target sequence in the protein coding region of c-Myc mRNA [24]), while distinct from other c-Myc targeting miRNAs such as miR-145, let7a, miR-24(target sites in 3'UTR of c-Myc [25-27]). However, the role of miR-320b in CRC is not fully understood because of the lack of target gene information. 
Our results demonstrated that c-Myc was directly targeted by miR-320b in CRC cells. Overexpression of miR-320b in CRC cells decreased both mRNA and protein levels of $c-M Y C$, a finding that is consistent with a previous work reporting a negative correlation of miR$320 \mathrm{~b}$ with various genes including $c-M Y C$ in CRC [28]. Our results suggest that miR-320b is a candidate tumor suppressor in the pathogenesis of CRC.

$c-M Y C$ is a node gene in multiple pathways, and most of its target genes including CCND1 are crucial for cell growth, proliferation and development [29-31]. As a regulator gene, $c-M Y C$ is carefully managed at different levels [32]. Recent studies have shown that the deregulation of miRNAs is responsible for high levels of c-Myc in many cancers. Several miRNA are known to be regulators of $\mathrm{c}-\mathrm{Myc}$ in various different cancers including miR-24 in leukemia [26], miR-145 in oral squamous cell carcinoma [25], let-7a in burkitt lymphoma [27], miR-34a in renal cell carcinoma [33] and miR-185-3p in CRC [24]. In this study, c-Myc was identified to be directly targeted, and regulated by miR-320b in CRC cells. Our results agreed with the viewpoint that a single mRNA molecule can been regulated by multiple miRNA genes in different cells $[34,35]$.

\section{Conclusions}

We conclude that miR-320b is frequently down regulated in CRC cell lines and clinical samples. Our data demonstrated that c-Myc was directly targeted and regulated by miR-320b, and that overexpression of miR-320b significantly inhibited CRC cells proliferation through regulating c-Myc. Our identification of c-Myc as a target of miR$320 \mathrm{~b}$ provides new insights into the pathophysiology of CRC proliferation and identifies miR-320b as a novel therapeutic targets for the treatment of CRC.

\section{Abbreviation}

CRC: Colorectal cancer; mRNA: Messenger RNA; qRT-PCR: Quantitative real-time PCR; miR-320b: MicroRNA-320b; IHC: Immunohistochemistry;

CLASH: Crosslinking, ligation, and sequencing of hybrids.

\section{Competing interests}

The authors declare that they have no competing interests.

\section{Authors' contributions}

CF conceived and designed the experiments. HW, FC, XL, HM, JE and JX performed the experiments. $F C$ and $X L$ collected the samples and analyzed the data. HW wrote the paper. All authors are in agreement with the content of the manuscript and this submission. All authors read and approved the final manuscript.

\section{Acknowledgements}

The study was supported by The National Natural Science Foundation of China (No. 81402005).

\section{Author details}

'Department of Colorectal Surgery, Changhai Hospital, Shanghai 200433, China. ${ }^{2}$ Department of General Surgery, The First People's Hospital of Pinghu, Pinghu 314200, Zhejiang Province, China.
Received: 24 December 2014 Accepted: 8 October 2015

Published online: 20 October 2015

\section{References}

1. Wilmink ABM. Overview of the epidemiology of colorectal cancer. Dis Colon Rectum. 1997:40:483-93.

2. Siegel R, Naishadham D, Jemal A. Cancer statistics. CA: a cancer journal for clinicians2013. 2013;63(1):11-30.

3. Bartel DP. MicroRNAs: genomics, biogenesis, mechanism, and function. Cell. 2004;116(2):281-97.

4. Cannell I, Kong Y, Bushell M. How do microRNAs regulate gene expression? Biochem Soc Trans. 2008;36(6):1224.

5. Bushati N, Cohen SM. microRNA functions. Annu Rev Cell Dev Biol. 2007;23:175-205.

6. Bartel DP. MicroRNAs: target recognition and regulatory functions. Cell. 2009;136(2):215-33.

7. Lu J, Getz G, Miska EA, Alvarez-Saavedra E, Lamb J, Peck D, et al. MicroRNA expression profiles classify human cancers. Nature. 2005;435(7043):834-8.

8. Dong $H$, Siu H, Luo L, Fang $X$, Jin L, Xiong M. Investigation gene and microRNA expression in glioblastoma. BMC Genomics. 2010;11 (Suppl 3):S16.

9. Chen CZ. MicroRNAs as oncogenes and tumor suppressors. N Engl J Med. 2005:353(17):1768

10. Calin GA, Croce CM. MicroRNA signatures in human cancers. Nat Rev Cancer. 2006;6(11):857-66.

11. Liu M, Chen H. The role of microRNAs in colorectal cancer. J Genet Genomics. 2010;37(6):347-58

12. Dong Y, Wu WKK, Wu CW, Sung JJY, Yu J, Ng SSM. MicroRNA dysregulation in colorectal cancer: a clinical perspective. Br J Cancer. 2011;104(6):893-8.

13. Roth P, Wischhusen J, Happold C, Chandran PA, Hofer S, Eisele G, et al. A specific miRNA signature in the peripheral blood of glioblastoma patients. J Neurochem. 2011;118(3):449-57.

14. Li X, Luo F, Li Q, Xu M, Feng D, Zhang G, et al. Identification of new aberrantly expressed miRNAs in intestinal-type gastric cancer and its clinical significance. Oncol Rep. 2011;26(6):1431-9.

15. Song T, Xia W, Shao N, Zhang X, Wang C, Wu Y, et al. Differential miRNA expression profiles in bladder urothelial carcinomas. Asian Pac J Cancer Prev. 2010;11(4):905-11.

16. Tai J, Wang G, Liu T, Wang L, Lin C, Li F. Effects of siRNA targeting C-Myc and VEGF on human colorectal cancer Volo cells. J Biochem Mol Toxicol. 2013;26(12):499-505.

17. Roy AL, Carruthers C, Gutjahr T, Roeder RG. Direct role for Myc in transcription initiation mediated by interactions with TFIII.I. Nature. 1993;365(6444):359-61.

18. Baldin V, Lukas J, Marcote MJ, Pagano M, Draetta G. Cyclin D1 is a nuclear protein required for cell cycle progression in G1. Genes Dev. 1993;7(5):812-21.

19. Schaar DG, Medina DJ, Moore DF, Strair RK, Ting Y. miR-320 targets transferrin receptor 1 (CD71) and inhibits cell proliferation. Exp Hematol. 2009:37(2):245-55.

20. Hsieh IS, Chang KC, Tsai YT, Ke JY, Lu PJ, Lee KH, et al. MicroRNA-320 suppresses the stem cell-like characteristics of prostate cancer cells by downregulating the Wnt/beta-catenin signaling pathway. Carcinogenesis. 2013;34(3):530-8.

21. Esquela-Kerscher A, Slack FJ. Oncomirs-microRNAs with a role in cancer. Nat Rev Cancer. 2006;6(4):259-69.

22. Kent OA, Mendell JT. A small piece in the cancer puzzle: microRNAs as tumor suppressors and oncogenes. Oncogene. 2006;25(46):6188-96.

23. Helwak A, Kudla G, Dudnakova T, Tollervey D. Mapping the human miRNA interactome by CLASH reveals frequent noncanonical binding. Cell. 2013;153(3):654-65.

24. Liao J-M, Lu H. Autoregulatory suppression of c-Myc by miR-185-3p. J Biol Chem. 2011;286(39):33901-9.

25. Shao Y, Qu Y, Dang S, Yao B, Ji M. MiR-145 inhibits oral squamous cell carcinoma (OSCC) cell growth by targeting c-Myc and Cdk6. Cancer Cell Int. 2013;13(1):51.

26. Lal A, Navarro F, Maher CA, Maliszewski LE, Yan N, O'Day E, et al. miR-24 inhibits cell proliferation by targeting E2F2, MYC, and other cell-cycle genes via binding to 3 UTR MicroRNA recognition elements. Mol Cell. 2009;35(5):610-25.

27. Sampson $\mathrm{VB}$, Rong $\mathrm{NH}$, Han J, Yang $\mathrm{Q}$, Aris V, Soteropoulos $\mathrm{P}$, et al. MicroRNA let-7a down-regulates MYC and reverts MYC-induced growth in Burkitt lymphoma cells. Cancer Res. 2007;67(20):9762-70. 
28. Fu J, Tang W, Du P, Wang G, Chen W, Li J, et al. Identifying MicroRNA-mRNA regulatory network in colorectal cancer by a combination of expression profile and bioinformatics analysis. BMC Syst Biol. 2012;6(1):68.

29. Arabi A, Wu S, Ridderstråle K, Bierhoff H, Shiue C, Fatyol K, et al. c-Myc associates with ribosomal DNA and activates RNA polymerase I transcription. Nat Cell Biol. 2005;7(3):303-10.

30. Grandori C, Gomez-Roman N, Felton-Edkins ZA, Ngouenet C, Galloway DA, Eisenman RN, et al. c-Myc binds to human ribosomal DNA and stimulates transcription of rRNA genes by RNA polymerase I. Nat Cell Biol. 2005;7(3):311-8.

31. Grewal SS, Li L, Orian A, Eisenman RN, Edgar BA. Myc-dependent regulation of ribosomal RNA synthesis during Drosophila development. Nat Cell Biol. 2005;7(3):295-302.

32. Secombe J, Pierce SB, Eisenman RN. Myc: a weapon of mass destruction. Cell. 2004;117(2):153-6.

33. Yamamura S, Saini S, Majid S, Hirata H, Ueno K, Chang I, et al. MicroRNA-34a suppresses malignant transformation by targeting c-Myc transcriptional complexes in human renal cell carcinoma. Carcinogenesis. 2012;33(2):294-300.

34. Lewis BP, Burge CB, Bartel DP. Conserved seed pairing, often flanked by adenosines, indicates that thousands of human genes are microRNA targets. Cell. 2005;120(1):15-20.

35. Krek A, Grün D, Poy MN, Wolf R, Rosenberg L, Epstein EJ, et al. Combinatorial microRNA target predictions. Nat Genet. 2005;37(5):495-500

\section{Submit your next manuscript to BioMed Central and take full advantage of:}

- Convenient online submission

- Thorough peer review

- No space constraints or color figure charges

- Immediate publication on acceptance

- Inclusion in PubMed, CAS, Scopus and Google Scholar

- Research which is freely available for redistribution 